Turoń-Skrzypińska Agnieszka, Dutkiewicz Grażyna, Marchelek-Myśliwiec Małgorzata, Rył Aleksandra, Uździcki Artur, Przybylski Tomasz, Rotter Iwona. Sclerostin - a potential new marker of exercise influence on vascular calcification and mineral and bone disorder in hemodialysed adults. Journal of Education, Health and Sport. 2019;9(12):67-74. eISSN 2391-8306. DOI http://dx.doi.org/10.12775/JEHS.2019.09.12.007

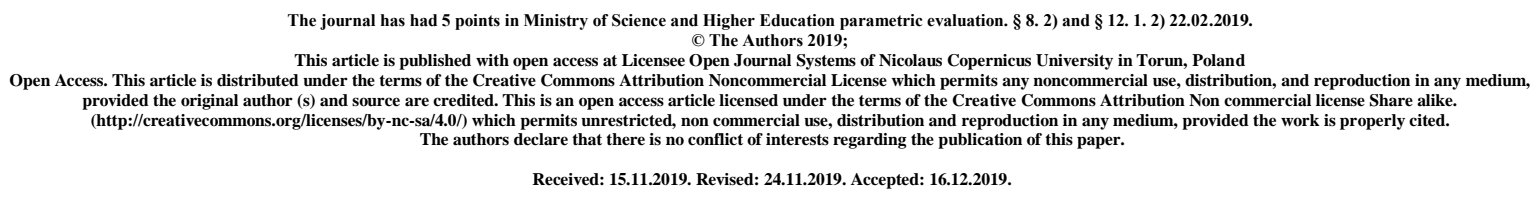

\title{
Sclerostin - a potential new marker of exercise influence on vascular calcification and mineral and bone disorder in hemodialysed adults
}

\author{
Agnieszka Turoń - Skrzypińska', Grażyna Dutkiewicz², \\ Małgorzata Marchelek - Myśliwiec ${ }^{2}$, Aleksandra Ryl ${ }^{2}$, Artur Uździcki ${ }^{3}$, \\ Tomasz Przybylski ${ }^{3}$, Iwona Rotter ${ }^{2}$ \\ ${ }^{1}$ Department of Medical Rehabilitation and Clinical Physiotherapy, Pomeranian Medical \\ ${ }^{2}$ Department of Nephrology, Transplantology and Internal Medicine, Pomeranian Medical \\ ${ }^{3}$ Student Scientific Society KINEZIS of the Department of Medical Rehabilitation and \\ Physiotherapy, Pomeranian Medical University
} University University Clinical

\begin{abstract}
Chronic Kidney Disease (CKD) is defined as abnormalities of kidney structure or function, present for $>3$ months, with implications for health. Amongst CKD complications the most fatal is cardiovascular disease, which together with Chronic Kidney Disease Mineral and Bone Disorder (CKD-MBD) share a possible origin in Wnt signaling pathway disturbances. Sclerostin, a potent Wnt signaling inhibitor may possibly be used as a potential new marker of exercise influence on vascular calcification and mineral and bone disorder in hemodialysed adults.
\end{abstract}

Key words: sclerostin; Chronic Kidney Disease Mineral and Bone Disorder; exercise

\section{Introduction}

Chronic Kidney Disease (CKD) is defined as abnormalities of kidney structure or function, present for $>3$ months, with implications for health. CKD diagnostic criteria includes either elevated GFR or presence of kidney damage, such as: albuminuria, urine sediment abnormalities, electrolyte and other abnormalities due to tubular disorders, abnormalities 
detected by histology, structural abnormalities detected by imaging or history of kidney transplantation [1]. Severity of CKD can be classified using estimated glomerular filtration rate (GFR), and one can distinguish 5 stages: Kidney damage with normal or increased GFR $\left(\right.$ GFR $\geq 90 \mathrm{ml} / \mathrm{min}$ per $\left.1.73 \mathrm{~m}^{2}\right)$, Kidney damage with mild decreased GFR (60-89), Moderately decreased GFR (30-59 ml/min per $1.73 \mathrm{~m}^{2}$ ), Severely decreased GFR (15-29 $\mathrm{ml} / \mathrm{min}$ per $1.73 \mathrm{~m}^{2}$ ) and Kidney failure (GFR less than $15 \mathrm{ml} / \mathrm{min}$ per $1.73 \mathrm{~m}^{2}$ ) [11]. Some studies suggest that even mild increase of serum creatinine may be associated with increased death rate from any cause[3]. CKD incidence is rising worldwide. In Europe, Japan and Australia screening surveys identified that the occurrence of CKD may be as high as 6 to 11\% [4]. Studies revealed that hypertension, diabetes, hyperlipidaemia, obesity, and smoking are considered to be risk factors of the CKD in the general population [5]. The character of the disease is progressive, and it may lead to end stage renal disease (ESRD), cardiovascular disease, and premature death [2]. Most patients with ESRD is treated with haemodialysis (HD) or peritoneal dialysis, despite that renal transplant is associated with longer life expectancy and better quality of life. Unfortunately, limited number of organ donors does not allow to perform more transplants [7]. As Chantrel F. et al. reports, for patients between 60 and 69 years old, for 1000 patients in dialysis in 2011, 127 died within the year, whereas for 1000 patients of the same age, who have a functioning kidney transplant, 24 died within the year [21].

Most ESRD patients receiving haemodialysis die from cardiovascular - related causes [8]. This is only partly explained by high prevalence of risk factors for atherosclerosis calcifications present in patients with mineral metabolism disorders occurring in progress of ESRD are also relevant, and has a prevalence rate of nearly $90 \%$ in ESRD patients $[9,10,42]$.

Another noteworthy condition related to CKD is Chronic Kidney Disease Mineral and Bone Disorder (CKD-MBD). It includes renal osteodystrophy and extraskeletal (vascular) calcification related to abnormalities of bone mineral metabolism. Classifying vascular calcifications together with bone metabolism abnormalities clearly shows that disturbances in calcium, inorganic phosphorus, vitamin D, PTH and FGF23 are responsible not only for increased risk of fractures, but also for increase of incidence cardiovascular complications. $[1,13]$. As it was proven, disturbance in mineral and bone metabolism in patients with CKD is an important cause of morbidity and decreased quality of life [6]. Many papers suggest that early treatment of CKD-MBD may result in improved management of CKD and it's complications [12].

Both the vascular calcifications and bone mineral density drop may result from enhanced activation of intracellular Wnt signalling pathway: Physiologically, Wnt signalling pathway is responsible for cell differentiation into osteoblasts, and there is evidence which suggests that pathological activation of Wnt signaling pathway may possibly be involved in CKDMBD [13,14]. A potent Wnt signaling pathway inhibitor, sclerostin is shown to be upregulated in atherosclerosis and in CKD [14,źródło na CKD]. Sclerostin is a protein, which is encoded by a SOST gene. Loss-of-function mutations in this gene are associated with an autosomal-recessive disorder, sclerosteosis, which causes progressive bone overgrowth, which is a consequence of lack of physiological, anti - anabolic function of sclerostin on bone tissue [23].

There is also evidence that exercise may lower the sclerostin concentrations in adults [17]. For HD patients regular exercise can provide numerous benefits, such as increasing selfreliance, improving mood, improving biochemical parameters taken into consideration when contemplating transplantation, but also decreases the risk of atherosclerosis and improves cardiovascular parameters $[18,19]$. 
In this paper we elucidate the possible role of sclerostin in CKD, but also the influence of physical activity on the sclerostin serum levels, and hypothesise if sclerostin might become a marker for physical activity influence on bone and cardiovascular health in HD patients.

\section{Sclerostin in Chronic Kidney Disease (CKD)}

An increase in sclerostin (SCL) serum concentration is observed from the 3rd stage of CKD, and in patients with end-stage renal failure it's concentration is several times higher than in patients with proper kidney function [38]. This is most likely due to the greatly increased production - it has been proven, that renal elimination of sclerostin increases with declining kidney function [37]. There is evidence that both bone tissue and vasculature participates in enhancement of the SCL production: Presence of the vascular calcification, even in coronary arteries, as seen in computed tomography and in pathology images has been linked to serum sclerostin concentration in numerous research, and the results acquired by both experimental methods were consistent [39,40,41,42]. Another studies may show possible correlation between increased risk of calcification of heart valves and high level of sclerostin in blood serum [50]. It is possible, that hyperphosphatemia, present in CKD, is associated with increased DNA methyltransferase activity and methylation of the promoter region of SM22 $\alpha$ gene, allowing more adaptability of vascular smooth muscle cells and simplified their transformation into osteoblast - like cells, which induce alkaline phosphatase activity, causing the vascular tissue mineralization process [43]. An expression of SCL in those osteoblast like cells has been proven, and they may contribute to SCL serum concentration [42]. However, it must be stated, that not all study results considering this matter are consistent - a negative correlation between SCL serum level and VC is also sometimes reported [42,44]. Qureshi A.R et al. reported no correlation between vascular SOST mRNA expression and circulating sclerostin levels, which means that vasculature may not be the primary source of serum SCL [41]. Another serum sclerostin source is the bone tissue - high levels of sclerostin correlate with increased BMD in dialysis patients, but high SCL production in bone tissue in CKD patients is not fully understood [46].

Despite the lack of consensus on the sclerostin source, it's concentration may be used as a marker of bone turnover - Boltenstål et al. demonstrated that serum and bone sclerostin are inversely associated with bone turnover and bone mass in CKD [48]. Cejka et al., presented a bone biopsy study of 60 hemodialysis patients, which shown the same conclusion - a negative correlation between bone formation rate and sclerostin levels. Authors stated, that SCL could be a useful biomarker for the prediction of high, but not low bone turnover [49]. That may indicate that a lower sclerostin serum concentration, which may be induced by proper physical activity may result in higher bone formation in HD adults.

\section{Influence of physical activity on sclerostin level in blood serum}

Microdamage of the bone tissue, as generally accepted, acts as a signal for a need of bone replacement. Therefore, exercise during which a mechanical load is inflicted to the bone generates microdamage, thus increases the anabolic activity of the bone tissue. Only recently it has been found, that microdamage to the bone tissue suppresses SOST gene expression and sclerostin production and therefore increases bone anabolism, potentiate repair processes and forming of new bone tissue [22,23,24]. Osteogenesis is therefore increased by the muscle contraction and relaxation, which in result inhibits the synthesis of sclerostin.

In study of Ardawi et al., premenopausal women performing physical activity for more than 120 min per week showed significantly lower serum sclerostin levels than sedentary controls [32]. Similar finding were described by Hinton et al., in which sclerostin concentrations in serum decreased by $7 \%$ in 12 months of resistance training twice a week or 12 months of 
completion of a jump protocol three times a week [33]. Janik et al. came up to comparable results in their study, in which sclerostin concentrations were lower by $12,04 \%$ in women at the age of 50-75 year after the 12 weeks of 40 minutes bike ergometer physical training 3 times per week [17].

There are also studies showing no effect of physical activity on sclerostin level. For example, Bergström et al. in their study depicted that even a year - long exercise program, which consisted of three fast 30-min walks and one or two 1-h aerobic training sessions per week, did not alter significantly sclerostin serum level in postmenopausal women [34].

Császárné Gombos et al. shown that serum sclerostin concentrations increased in participants in the resistance exercise group and walking group compared to its base level [29]. Additionally, the study of Falk et al., in which blood samples were taken after plyometric exercises and the study of Sharma-Ghimire et al., in young women researched response to the whole-body vibration and high intensity resistance exercise also came to the conclusion that sclerostin concentrations increased after acute exercise [30,31]. When considering studies depicting acute exercise one must notice that those studies most often don't include long term variability. In study conducted by Kouvelitoli sclerostin concentration increased from pre-exercise to $5 \mathrm{~min}$ after exercise and returned to baseline levels by $1 \mathrm{~h}$ - as authors conclude it is difficult to extrapolate from one, acute exercise bout, how the body adapts to chronic training [26]. Katelyn I. Guerriereno et al. claimed that this difference may result from other mediators of sclerostin production such as estrogen and PTH. Guerriereno conducted a study in which fluctuations in serum Ca were minimised using dietary approach, showing no significant response in serum concentrations of sclerostin related to an acute bout of plyometric jump exercise in young, healthy men [28]. KerschanSchindl et al. shown in their study that despite sclerostin concentration did not significantly differ before and after the $246 \mathrm{~km}$ race, serum sclerostin levels decreased during the followup period [35].

Despite numerous differences in study results, it seems that sclerostin serum concentration level decreases after taking up a long - term, regular exercise. Moreover, the type of training, its duration, the number of repetitions of a given exercise, frequency and load influence the concentration of sclerostin in the blood $[25,27]$

\section{The possible role of sclerostin as physical activity intensity marker in HD patients}

Overall, most studies show, that sclerostin levels are associated with cardiovascular calcification and mortality [45]. However sclerostin levels are in some studies positively related to higher bone mineral density in CKD patients, it may only be an evidence of an upregulation due to a lack of sufficient inhibition of Wnt signaling pathway. Noteworthy, each study used a different method to assay serum sclerostin levels [16]. It is shown, that physical activity lowers the serum concentration of sclerostin in HD patients, despite it's well proven role in maintaining high bone mineral density in adults [17,22]. It is possible that a sufficient amount of physical activity in HD patients may lower sclerostin levels, without influencing negatively neither cardiovascular nor bone symptoms. Possibly, while maintaining proper physical activity during HD an increase of serum sclerostin level from the patient's baseline may indicate a need of additional CKD -MBD treatment or of modification of physical activity intensity. This has partially been proven using an animal model of mild CKD - moderate-intensity exercise reduced serum sclerostin levels and bone resorption rate [36]. All this possibilities indicate a strong need in research in this field. Fortunately, the interest in Wnt signaling pathway inhibitors in nephrology is constantly rising. [20]. 


\section{Bibliography}

1. Kidney Disease: Improving Global Outcomes (KDIGO) CKD Work Group: KDIGO 2012 clinical practice guideline for the evaluation and management of chronic kidney disease. Kidney International Supplements, 2013; 3: 1-150.

2. Coresh J, Selvin E, Stevens LA, et al. Prevalence of Chronic Kidney Disease in the United States. JAMA. 2007;298(17):2038-2047. doi:https://doi.org/10.1001/jama.298.17.2038

3. Culleton BF, Larson MG, Wilson PW, Evans JC, Parfrey PS, Levy D. Cardiovascular disease and mortality in a community-based cohort with mild renal insufficiency. Kidney Int 1999;56:2214-2219

4. A Meguid El Nahas, Aminu K Bello, Chronic kidney disease: the global challenge, The Lancet, Volume 365, Issue 9456, 2005, Pages 331-340, ISSN 0140-6736.

5. Klag MJ, Whelton PK, Randall BL, et al. End-stage renal disease in AfricanAmericans and white men: 16-year MRFIT findings. JAMA 1997; 277: 1293-98

6. Sharon M. Moe, Tilman Drüeke, Norbert Lameire, Garabed Eknoyan, Chronic Kidney Disease-Mineral-Bone Disorder: A New Paradigm, Advances in Chronic Kidney Disease, Volume 14, Issue 1, 2007, Pages 3-12, ISSN 1548-5595.

7. Mehrotra R, Chiu Y, Kalantar-Zadeh K, Bargman J, Vonesh E. Similar Outcomes With Hemodialysis and Peritoneal Dialysis in Patients With End-Stage Renal Disease. Arch Intern Med. 2011;171(2):110-118.

8. Alfred-Demas, R.; Moore, B.; Trim, A.; Sandy-Robinson, A.; Wasunna, A.Cardiovascular Parameters in Chronic Haemodialysis Patients in Tobago. West Indian Medical Journal . 2018, Vol. 67 Issue 2, p157-159. 3p.

9. Longenecker JC, Coresh J, Powe NR et al. Traditional cardiovascular disease risk factors in dialysis patients compared with the general population: the CHOICE Study. J Am Soc Nephrol 2002; 13: 1918-1927.

10. Glenn M. Chertow, Paolo Raggi, Scott Chasan-Taber, Juergen Bommer, Herwig Holzer, Steven K. Burke, Determinants of progressive vascular calcification in haemodialysis patients, Nephrology Dialysis Transplantation, Volume 19, Issue 6, June 2004, Pages 14891496.

11. Levey AS, Coresh J, Balk E, et al. National Kidney Foundation Practice Guidelines for Chronic Kidney Disease: Evaluation, Classification, and Stratification. Ann Intern Med. 2003;139:137-147.

12. Early Control of PTH and FGF23 in Normophosphatemic CKD Patients: A New Target in CKD-MBD Therapy? Rodrigo B. Oliveira, Ana L.E. Cancela, Fabiana G. Graciolli, Luciene M. Dos Reis, Sérgio A. Draibe, Lilian Cuppari, Aluizio B. Carvalho, Vanda Jorgetti, Maria E. Canziani, Rosa M.A. Moysés CJASN Feb 2010, 5 (2) 286-291; DOI: 10.2215/CJN.05420709.

13. Mario Cozzolino, Pablo Ureña-Torres, Marc G. Vervloet, Vincent Brandenburg, Jordi Bover, David Goldsmith, Tobias E. Larsson, Ziad A. Massy, Sandro Mazzaferro, on behalf of the CKD-MBD Working Group of ERA-EDTA, Is chronic kidney disease-mineral bone disorder (CKD-MBD) really a syndrome?, Nephrology Dialysis Transplantation, Volume 29, Issue 10, October 2014, Pages 1815-1820.

14. Thambiah, S., Roplekar, R., Manghat, P., Fogelman, I., Fraser, W. D., Goldsmith, D., \& Hampson, G. (2012). Circulating sclerostin and Dickkopf-1 (DKK1) in predialysis chronic kidney disease (CKD): relationship with bone density and arterial stiffness. Calcified tissue international, 90(6), 473-480.

15. Takuo Kubota, Toshimi Michigami, Keiichi Ozono. Wnt signaling in bone metabolism. J Bone Miner Metab (2009) 27:265-271. 
16. Thambiah, S., Roplekar, R., Manghat, P., Fogelman, I., Fraser, W. D., Goldsmith, D., \& Hampson, G. (2012). Circulating sclerostin and Dickkopf-1 (DKK1) in predialysis chronic kidney disease (CKD): relationship with bone density and arterial stiffness. Calcified tissue international, 90(6), 473-480.

17. Janik, M., Stuss, M., Michalska-Kasiczak, M., Jegier, A., \& Sewerynek, E. (2018). Effects of physical activity on sclerostin concentrations. Endokrynologia Polska, 69(2), 142149.

18. Chung Y.C., Yeh M.L., Liu Y.M.: Effects of intradialytic exercise on the physical function, depression and quality of life for haemodialysis patients: a systematic review and meta-analysis of randomised controlled trials. J Clin Nurs 2017; 26 (13-14): 1801-1813. Dostępny w: doi: 10.1111/jocn.13514.

19. Kong C.H., Tattersall J.E., Greenwood R.N., Farrington K.: The effect of exercise during haemodialysis on solute removal. Nephrol Dial Transplant 1999; 14 (12): 2927-2931.

20. Emilia Mierzwińska, Tomasz Hryszko, Emilia Szablak-Uliszewska, Beata Naumnik. Sklerostyna i przewlekła choroba nerek. Postepy Hig Med Dosw 2017; 71 : 1098-1106.

21. Chantrel, F., Deloumeaux, J., Lange, C., \& Lassalle, M. (2013). Survival and mortality in ESRD patients. Nephrologie \& therapeutique, 9, S127-37.

22. Boyde, A. (2003). The real response of bone to exercise. Journal of anatomy, 203(2), 173-189.

23. Association of SOST gene polymorphisms with peak bone mineral density in Chinese nuclear families with male-offspring. Qi L, et al. Acta Biochim Biophys Sin (Shanghai), 2019 Mar 1. PMID 30883645.

24. Guerriere, K. I., Hughes, J. M., Gaffney-Stomberg, E., Staab, J. S., \& Matheny Jr, R. W. (2018). Circulating sclerostin is not suppressed following a single bout of exercise in young men. Physiological reports, 6(10), e13695.

25. Clarke B.L., Drake M.T.: Clinical utility of serum sclerostin measurements. Bonekey Rep 2013; 2: 361.

26. Kouvelioti R, Kurgan N, Falk B, Ward WE, Josse AR, Klentrou P. Response of Sclerostin and Bone Turnover Markers to High Intensity Interval Exercise in Young Women: Does Impact Matter?. Biomed Res Int. 2018;2018:4864952. Published 2018 Nov 1. doi:10.1155/2018/4864952.

27. Lombardi G., Lanteri P., Colombini A., Mariotti M., Banfi G.: Sclerostin concentrations in athletes: role of load and gender. J Biol Regul Homeost Agents 2012; 26 (1): $157-163$.

28. Guerriere, K. I., Hughes, J. M., Gaffney-Stomberg, E., Staab, J. S., \& Matheny, R. W. (2018). Circulating sclerostin is not suppressed following a single bout of exercise in young men. Physiological Reports, 6(10), e13695.

29. Gombos GC, Bajsz V, Pék E, et al. Direct effects of physical training on markers of bone metabolism and serum sclerostin concentrations in older adults with low bone mass. BMC Musculoskelet Disord. 2016;17:254. Published 2016 Jun 8. doi:10.1186/s12891-0161109-5.

30. Falk B, Haddad F, Klentrou P, et al. Differential sclerostin and parathyroid hormone response to exercise in boys and men. Osteoporos Int. 2016;27(3):1245-1249. doi:10.1007/s00198-015-3310-z.

31. Sharma-Ghimire, P., Chen, Z., Sherk, V., Bemben, M., \& Bemben, D. (2019). Sclerostin and parathyroid hormone responses to acute whole-body vibration and resistance exercise in young women. Journal of bone and mineral metabolism, 37(2), 358-367.

32. Ardawi, M. S. M., Rouzi, A. A., \& Qari, M. H. (2012). Physical activity in relation to serum sclerostin, insulin-like growth factor-1, and bone turnover markers in healthy 
premenopausal women: a cross-sectional and a longitudinal study. The Journal of Clinical Endocrinology \& Metabolism, 97(10), 3691-3699.

33. Hinton PS, Nigh P, Thyfault J. Serum sclerostin decreases following 12 months of resistance- or jump-training in men with low bone mass. Bone. 2017;96:85-90. doi:10.1016/j.bone.2016.10.011.

34. I. Bergstrom, P. Parini, S.A. Gustafsson, G. Andersson, J. Brinck, Physical training increases osteoprotegerin in postmenopausal women. J. Bone Miner. Metab. 30(2), 202-207 (2012)

35. Kerschan-Schindl K, Thalmann MM, Weiss E, et al. Changes in Serum Levels of Myokines and Wnt-Antagonists after an Ultramarathon Race. PLoS One. 2015;10(7):e0132478. Published 2015 Jul 6. doi:10.1371/journal.pone.0132478

36. Liao, H. W., Huang, T. H., Chang, Y. H., Liou, H. H., Chou, Y. H., Sue, Y. M., ... \& Tsai, K. J. (2019). Exercise Alleviates Osteoporosis in Rats with Mild Chronic Kidney Disease by Decreasing Sclerostin Production. International journal of molecular sciences, 20(8), 2044.

37. Cejka D., Marculescu R., Kozakowski N., Plischke M., Reiter T.,Gessl A., Haas M.: Renal elimination of sclerostin increases with declining kidney function. J. Clin. Endocrinol. Metab., 2014; 99: 248-255.

38. Desjardins L., Liabeuf S., Oliveira R.B., Louvet L., Kamel S., Lemke H.D., Vanholder R., Choukroun G., Massy Z.A., European Uremic Toxin (EUTox) Work Group: Uremic toxicity and sclerostin in chronic kidney disease patients. Nephrol. Ther., 2014; 10: 463-470.

39. Morena M, Jaussent I, Dupuy AM, et al. Osteoprotegerin and sclerostin in chronic kidney disease prior to dialysis: potential partners in vascular calcifications. Nephrol Dial Transplant 2015; 30: 1345-1356.

40. Lv W., Guan L., Zhang Y., Yu S., Cao B., Ji Y.: Sclerostin as new key factor in vascular calcification in chronic kidney disease stages 3 and 4. Int. Urol. Nephrol., 2016; 48: 2043-2050.

41. Qureshi A.R., Olauson H., Witasp A., Haarhaus M., Brandenburg, V., Wernerson A., Lindholm B., Söderberg M., Wennberg L., Nordfors L., Ripsweden J., Barany P., Stenvinkel P.: Increased circulating sclerostin levels in end-stage renal disease predict biopsy-verified vascular medial calcification and coronary artery calcification. Kidney Int., 2015; 88: 13561364.

42. Li, M., Zhou, H., Yang, M., \& Xing, C. (2019). Relationship between serum sclerostin, vascular sclerostin expression and vascular calcification assessed by different methods in ESRD patients eligible for renal transplantation: a cross-sectional study. International urology and nephrology, 51(2), 311-323.

43. Byon $\mathrm{CH}$, Chen Y. Molecular mechanisms of vascular calcification in chronic kidney disease: the link between bone and the vasculature. Curr Osteoporos Rep. 2015;13:206-215.

44. Evenepoel P, Goffin E, Meijers B, Kanaan N, Bammens B, Coche E, Claes K, Jadoul M (2015) Sclerostin serum levels and vascular calcification progression in prevalent renal transplant recipients. J Clin Endocrinol Metab 100(12):4669-4676.

45. Nguyen-Yamamoto L, Tanaka KI, St-Arnaud R, Goltzman D. Vitamin D-regulated osteocytic sclerostin and BMP2 modulate uremic extraskeletal calcification. JCI Insight. 2019;4(13):e126467. Published 2019 Jul 11. doi:10.1172/jci.insight.126467.

46. Mödder UI, Hoey KA, Amin S, et al. Relation of age, gender, and bone mass to circulating sclerostin levels in women and men, J Bone Miner Res , 2011, vol. 26 (pg. 373379).

47. Daniel Cejka, Agnes Jäger-Lansky, Heidi Kieweg, Michael Weber, Christian Bieglmayer, Dominik G. Haider, Danielle Diarra, Janina M. Patsch, Franz Kainberger, 
Barbara Bohle, Martin Haas, Sclerostin serum levels correlate positively with bone mineral density and microarchitecture in haemodialysis patients, Nephrology Dialysis Transplantation, Volume 27, Issue 1, January 2012, Pages 226-230.

48. Boltenstål, H., Qureshi, A. R., Behets, G. J., Lindholm, B., Stenvinkel, P., D’Haese, P. C., \& Haarhaus, M. (2019). Association of Serum Sclerostin with Bone Sclerostin in Chronic Kidney Disease is Lost in Glucocorticoid Treated Patients. Calcified tissue international, 104(2), 214-223.

49. Cejka, D., Herberth, J., Branscum, A.J. et al. Sclerostin and Dickkopf-1 in renal osteodystrophy. Clin J Am Soc Nephrol. 2011; 6: 877-882.

50. Ji, Y. Q., Guan, L. N., Yu, S. X., Yin, P. Y., Shen, X. Q., Sun, Z. W., ... \& Ren, C. (2018). Serum sclerostin as a potential novel biomarker for heart valve calcification in patients with chronic kidney disease. European review for medical and pharmacological sciences, 22(24), 8822-8829. 